\title{
Role of Concurrent Methylation Pattern of MGMT, TP53 and CDKN2A Genes in the Prognosis of High Grade Glioma
}

Jeru-Manoj Manuel ${ }^{1}$, Debarati Ghosh ${ }^{1}$, Narasinga Rao KVL ${ }^{2}$, Sibin MK ${ }^{1}$, Venkatesh HN ${ }^{1}$, Lavanya Ch $^{1}$, Arati $\mathbf{S}^{1}$, Dhananjaya I Bhat ${ }^{2}$, Srinivas Bharath MM ${ }^{3}$, Chetan $\mathrm{GK}^{1^{*}}$

${ }^{1}$ Department of Human Genetics, National Institute of Mental Health and Neurosciences (NIMHANS), Bangalore-560029, India

${ }^{2}$ Department of Neurosurgery, National Institute of Mental Health and Neurosciences (NIMHANS), Bangalore-560029, India

${ }^{3}$ Department of Neurochemistry, National Institute of Mental Health and Neurosciences (NIMHANS), Bangalore-560029, India

*Corresponding author: Chetan GK, Department of Human Genetics, National Institute of Mental Health and Neurosciences (NIMHANS), Bangalore-560029, India, Tel: +91-080-26995782; E-mail: drchetangk@gmail.com

Received date: December 27, 2015; Accepted date: January 22, 2016; Published date: January 25, 2016

Copyright: (c) 2016 Jeru-Manoj, et al, et al. This is an open-access article distributed under the terms of the Creative Commons Attribution License, which permits unrestricted use, distribution, and reproduction in any medium, provided the original author and source are credited.

\begin{abstract}
Objective: High grade glioma (HGG) patients show poor prognosis and survival. Promoter methylation of MGMT gene induces altered methylation profile across cell cycle regulating genes. Correlating the promoter methylation status between important tumor suppressor genes could enhance the current understanding of glioma progression.
\end{abstract}

Methods: We analysed individual and concurrent methylation statuses' of three tumor suppressor genes, MGMT, TP53 and CDKN2A in different types of HGG and their probable effect on progression free survival. MS-PCR was used to analyse the methylation statuses from 48 HGG tumor samples.

Results: Promoter methylation was observed in $89.5 \%$ (43/48) of our cohort in atleast one of the genes, most frequent in MGMT (75\%), followed by CDKN2A (35.4\%) and TP53 (29.2\%). MGMT methylation and TP53 unmethylation individually were significant $(p=0.001$ and 0.016$)$ for PFS at 14 months. MGMT methylation with therapy (RT/CT+RT) was seen to improve PFS. Concurrent methylation was notably seen in oligodendroglial tumors, the frequency between MGMT: TP53 was 20.83\%, MGMT: CDKN2A (27.1\%) and TP53:CDKN2A (14.6\%). Interestingly, concurrent methylation of MGMT: TP53:CDKN2A (12.5\%) had better 14 month-PFS proportion $(80 \%)$.

Conclusion: Two gene concurrent methylation of MGMT along with either TP53 or CDKN2A decreased the PFS rate, indicating the negative effect of methylation of TP53 or CDKN2A. However, concurrent methylation of all three genes had better prognosis, but could be mainly due to influence of MGMT methylation This study highlights the importance of assessing concurrent promoter methylation and checking its correlation with survival status among HGG.

Keywords: High grade glioma; $\mathrm{CpG}$ promoter methylation; DNA repair; Tumour suppressor genes; MGMT; TP53; CDKN2A; Concurrent methylation

\section{Abbreviations \\ HGG: High Grade Glioma; TSG: Tumor Suppressor Genes; MGMT: O-6-Methylguanine DNA Methyltransferase; TP53: Tumor Protein 53; CDKN2A: Cyclin Dependent Kinase Inhibitor 2A; AOD: Anaplastic Oligodendroglioma; AOA: Anaplastic Mixed Oligoastrocytoma; AA: Anaplastic Astrocytoma; AE: Anaplastic Ependymomas; GB: Glioblastoma; PFS: Progression Free Survival; OS: Overall Survival}

\section{Introduction}

Human high grade glioma (HGG) are Grade III and Grade IV tumors (WHO, 2007) [1], that are aggressive and malignant contributing to about $2 \%-10 \%$ of all cancers [2]. These tumors are highly resistant to chemotherapy and radiotherapy, therefore patients with HGG show poor progression free survival (PFS) and overall survival (OS) $[3,4]$. The current standard of treatment includes, chemotherapy with alkylating agents such as temozolomide (TMZ) along with radiotherapy [4], but most patients' exhibit rapid disease progression.

Alkylating agents are known to induce reversible DNA damage mediated through epigenetic changes [5]. Epigenetic mechanisms such as $\mathrm{CpG}$ island methylation or histone modifications regulate gene expression [6]. Aberrant CpG island promoter methylation silences DNA repair as well as tumor suppressor genes, inducing a CpG island mutator phenotype which leads to progression of glioma [7]. These modifications are widely studied and observed more predominantly in HGG [8]. MGMT (O-6-methylguanine-DNA methyltransferase) is the direct DNA repair gene with tumor suppressing function which protects cells against damaging lesions caused by alkylation of DNA at the O-6 position of guanine [9]. MGMT transfers the methyl group to an active cysteine within its own sequence and gets inactivated. Promoter methylation has been identified as the key mechanism of MGMT gene silencing, it rarely undergoes any other mutation or deletion [10]. MGMT promoter methylation is currently used as a prognostic and predictive biomarker in glioblastoma, especially those treated with TMZ [11]. Report suggests median PFS for glioblastoma patients with methylated MGMT promoter is 11.8 months, whereas for patients with unmethylated promoter it is 8.3 months [12]. Thus, 
Citation: Jeru-Manoj Manuel, Debarati Ghosh, Narasinga Rao KVL, Sibin MK, Venkatesh HN (2016) Role of Concurrent Methylation Pattern of MGMT, TP53 and CDKN2A Genes in the Prognosis of High Grade Glioma. J Carcinog Mutagene 7: 250. doi: $10.4172 / 2157-2518.1000250$

Page 2 of 8

MGMT promoter methylation is one among the important biomarkers considered for treatment response and to assess survival status, especially in HGG [13].

Relevance of MGMT methylation mediated gene silencing extends beyond the prediction of chemo-sensitivity and reflects a distinct epigenetic profile [14]. Alterations of the global genome methylation by creation of an irregular methylation pattern (formation of O-6methylguanine adducts) are observed, especially in cancer cells [15]. Persistence of these adducts causes DNA polymerase to misread the base pairing resulting in accumulation of damages [9]. Increased accumulation of adduct formation in promoter region of cell cycle regulating genes leads to tumorigenesis [16].

Hypermethylation of the promoter regions of tumor suppressor genes (TSGs) has been associated with transcriptional silencing and tumor progression [17]. Tumor protein p53 (TP53), one of the key tumor suppressor genes, is known to promote apoptosis, inhibit cell cycle progression, senescence, differentiation and also accelerates DNA repair [18]. Mutations in TP53 were among the first genetic alterations identified in astrocytic brain tumors [19], but the significance of TP53 as a prognostic factor in GB remains unclear [18]. A possible relationship between MGMT gene expression and TP53 have been suggested previously $[11,20]$. Several studies have provided conflicting results about the association between the expression of TP53 and MGMT [20,21]. Changes in TP53 non-CpG and CpG dinucleotides could be attributable to silencing of MGMT that allows the persistence of O-6-methylguanine and it being read as an adenine [22]. Contradicting reports state MGMT downregulation is associated with TP53 mutations and, TP53 gene over expression down regulate MGMT and vice versa, stating both a direct as well as indirect correlation [20,23,24]. However, there is little information about concurrent methylation pattern of both TP53 and MGMT in glioma [25].

CDKN2A (Cyclin dependent kinase inhibitor 2A/p16) bears a striking resemblance to the paradigmatic tumor suppressor gene, TP53 [26]. This gene codes for a protein that binds to and inhibits cyclin $\mathrm{D}$ kinase (Cdk4 and Cdk6), which phosphorylate serine and threonine residues of the retinoblastoma $(\mathrm{Rb})$ protein [27]. Therefore, the p16 protein inhibits cell cycle progression through G1 to $S$ phase by maintaining the $\mathrm{Rb}$ protein in the unphosphorylated state [28]. Inactivation of CDKN2A gene expression by aberrant promoter methylation is believed to play a role in the pathway to tumorigenesis, and is frequently reported in many types of head and neck tumors $[27,29]$. The present study was carried out to explore and understand the association of individual promoter methylation status, and concurrent methylation pattern between each of the above mentioned genes. Correlation with the progression of glioma and thereby its impact on survival across different histological types of HGG were also analysed.

\section{Patients and Methods}

\section{Subjects}

Post-surgery excised primary HGG tissues from 48 adult patients with no family history of glioma aged between 18 years- 72 years (Male: 38, Female: 10), who underwent surgery in the department of Neurosurgery, NIMHANS, Bangalore during 2011 to 2014, were used in the present study. Pre-operative peripheral blood (internal control) with prior informed consent as per the guidelines of Institution ethical committee, in accordance with ethical standards was obtained. The resected tumor tissues were bisected; one half was stored in RNAlater (Sigma, Missouri, USA) for further experiments. Another half was fixed in $10 \%$ buffered neutral formalin, processed for paraffin section, and was used for histopathological grading, which was carried out at the Department of Neuropathology, NIMHANS.

\section{DNA isolation and quantification}

Histologically diagnosed tissues which contained $>95 \%$ tumor cells were used for the genetic analysis. DNA isolation was carried out for tissue samples using Genomic Prep Cells and Tissue DNA Isolation Kit (illustra $^{\text {ma }}$ GE Healthcare UK limited, Buckinghamshire, UK) and Genomic Prep ${ }^{\text {Tx }}$ Blood DNA Isolation Kit (illustra ${ }^{\text {Tx }}$ GE Healthcare UK limited, Buckinghamshire, UK) for blood samples. DNA was quantified using Nanodrop ND 2000c (Thermo Scientific, Wilmington, USA), and samples having purity of 1.8-1.99 (A260/280) were selected for the study.

\section{Methylation-specific PCR (MS-PCR)}

Bisulphite conversion of DNA (500-1000ng of DNA) for CpG promoter methylation analysis was carried out using EpiTect Bisulphite kit (Qiagen, Hilden, Germany). Methylation-specific PCR (MS-PCR) was performed on the sodium-bisulphite treated DNA samples to amplify the promoter region of the following genes: MGMT, TP53 and CDKN2A. Two pairs of primers (one for methylated and another for unmethylated sequences) were used for each promoter region as described $[8,25]$. MS-PCR was performed under standard conditions using Amplitaq Gold (Applied Biosystems, Foster city, USA) master mix, 35 cycles at annealing temperature of $56^{\circ} \mathrm{C}$ for MGMT, $55^{\circ} \mathrm{C}$ for TP53 and $60^{\circ} \mathrm{C}$ for CDKN2A respectively, primers of $0.2 \mu \mathrm{M}$ was used for all reactions. For each PCR, bisulphite converted DNA isolated from methylated cell line (U87MG cell line) was used as positive methylation control (cultured in laboratory), and converted DNA obtained from peripheral blood as positive unmethylated control. Nuclease free water was used as negative controls. PCR products were separated on agarose gels and visualized using Syngene G: Box F3 gel documentation system, powered by Genesys (Version 4.0) software (Gurgaon, India). MS-PCR was repeated to confirm the results and ensure they were replicable.

\section{Statistical analysis}

Statistical analysis was carried out using MedCalc (version 14.12.0) trial version software. Descriptive statistics was calculated for all variables in the study. Association between categorical variables was analysed using Fisher's exact test. Univariate survival analysis was carried out using Kaplan-Meier survival curve (Log rank test). Multivariate analysis was performed using Cox proportional regression analysis (stepwise). Correlation of Progression free survival (PFS) and Overall survival (OS) at 14 months with different variables were the end-point analysis studied. $\mathrm{P}$ value less than 0.05 was considered as significant for all analysis.

\section{Results}

\section{Demographic profile}

The mean age of our cohort was $41.6 \pm 15.4$ years. Tumor location was predominant in the frontal lobe (64.5\%). Occurrence of grade III tumors were significantly seen in the age group $\leq 40$ years, and grade 
Citation: Jeru-Manoj Manuel, Debarati Ghosh, Narasinga Rao KVL, Sibin MK, Venkatesh HN (2016) Role of Concurrent Methylation Pattern of MGMT, TP53 and CDKN2A Genes in the Prognosis of High Grade Glioma. J Carcinog Mutagene 7: 250. doi: $10.4172 / 2157-2518.1000250$

Page 3 of 8

IV tumors in $>40$ years $(\mathrm{p}=0.001) .30$ patients from the cohort underwent post surgery adjuvant therapy (Chemotherapy with TMZ+ RT: 21 and only RT: 9). Overall PFS and OS was better for patients with age $\leq 40$ irrespective of adjuvant therapy (Table1).

\begin{tabular}{|c|c|c|c|c|c|c|c|c|}
\hline \multicolumn{2}{|c|}{ Variables } & \multirow{2}{*}{$\begin{array}{l}\text { No. of } \\
\text { patients }\end{array}$} & \multicolumn{2}{|c|}{ MGMT } & \multicolumn{2}{|c|}{ TP53 } & \multicolumn{2}{|c|}{ CDKN2A } \\
\hline & & & M & u & $\mathbf{M}$ & U & M & U \\
\hline \multicolumn{9}{|c|}{ Age } \\
\hline \multicolumn{2}{|c|}{$\leq 40$ years } & 25 & 17 & 8 & 8 & 17 & 9 & 16 \\
\hline \multicolumn{2}{|c|}{$>40$ years } & 23 & 19 & 4 & 6 & 17 & 8 & 15 \\
\hline \multicolumn{9}{|c|}{ Position } \\
\hline \multicolumn{2}{|c|}{ Frontal } & 31 & 24 & 7 & 10 & 21 & 13 & 18 \\
\hline \multicolumn{2}{|c|}{ Others } & 17 & 12 & 5 & 4 & 13 & 4 & 13 \\
\hline \multicolumn{9}{|c|}{ Grade \& type } \\
\hline \multirow[t]{5}{*}{ III } & AOD & 15 & 10 & 5 & 7 & 8 & 8 & 7 \\
\hline & AOA & 11 & 9 & 2 & 3 & 7 & 3 & 8 \\
\hline & $\mathrm{AE}$ & 3 & 1 & 2 & 0 & 3 & 0 & 3 \\
\hline & AA & 2 & 2 & 0 & 0 & 3 & 0 & 2 \\
\hline & Total & 31 & 22 & 9 & 10 & 21 & 11 & 20 \\
\hline \multicolumn{2}{|c|}{ IV - GB } & 17 & 14 & 3 & 4 & 13 & 6 & 11 \\
\hline \multicolumn{9}{|c|}{ Post-surgery treatment } \\
\hline \multicolumn{2}{|c|}{$\mathrm{CT}+\mathrm{RT}$} & 21 & 17 & 4 & 6 & 15 & 9 & 12 \\
\hline \multicolumn{2}{|c|}{ RT } & 9 & 7 & 2 & 3 & 6 & 1 & 8 \\
\hline \multicolumn{2}{|c|}{ No } & 18 & 12 & 6 & 5 & 11 & 7 & 11 \\
\hline
\end{tabular}

Table 1: Patient characteristics (Age, Position, Grade, Histology type, and Treatment information) wise Individual Methylation status of MGMT, TP53 and CDKN2A.

\section{Promoter methylation status}

MS-PCR of 48 HGG patients revealed methylation of at least one gene in 43 samples (89.5\%). Methylation was absent in peripheral blood samples for all three genes (Figure 1.A.B.C). There was no significant correlation between individual promoter methylation status with age of patients, position and type of tumors (Table 2). MGMT promoter methylation was observed in 36 samples (75\%). Grade wise methylation analysis revealed 22 out of $31(71 \%)$ grade III tumors and 14 out of 17 (82.4\%) grade IV tumors to be MGMT methylated. TP53 promoter methylation was seen in 14 samples $(29.2 \%), 10$ out of 31 (32.25\%) were grade III and 4 out of 17 (23.5\%) were grade IV tumors. CDKN2A promoter methylation was seen in 17 samples (35.4\%). 11 out of $31(35.5 \%)$ were grade III tumors and 6 out of 17 (35.3\%) were grade IV tumors.

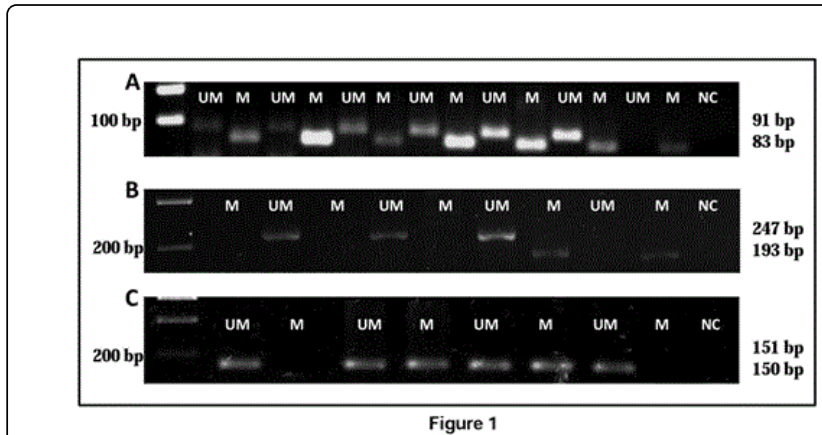

Figure 1: Representative gel images of high grade glioma (AOD and GB) samples. Fig 1A 3\% agarose gel shows methylated (83 bp) and unmethylated (91 bp) samples for MGMT gene promoter Fig 1B $2.5 \%$ agarose gel shows methylated (193 bp) and unmethylated (247 bp) promoter of TP53 gene Fig 1C $2 \%$ agarose gel shows CDKN2A gene's methylated (150bp) and unmethylated (151bp) promoters.

\section{Concurrent promoter methylation status between MGMT, TP53 and CDKN2A genes}

Frequency of concurrent methylation between MGMT:TP53 is $20.83 \%(10 / 48)$, between MGMT: CDKN2A is $27.1 \%(13 / 48)$ and TP53:CDKN2A is $14.6 \%$ (7/48). Tumor type had an association with the concurrent methylation pattern between MGMT: TP53 and MGMT:CDKN2A genes (Figure 2A \& 2B). The distribution of concurrent methylation pattern was similar in MGMT:TP53 and MGMT:CDKN2A, notably seen in oligodendroglial (AOD) type of tumors. Whereas, the concurrent methylation of TP53:CDKN2A had a different distribution pattern (Figure 2C). Three gene concurrent methylation (MGMT:TP53:CDKN2A) was seen in 12.5\% (6/48). Interestingly, concurrent methylation pattern (i.e., either methylated or unmethylated) of these three genes, was seen only in grade III mainly oligodendroglial tumors with significant PFS value (Figure 2D).

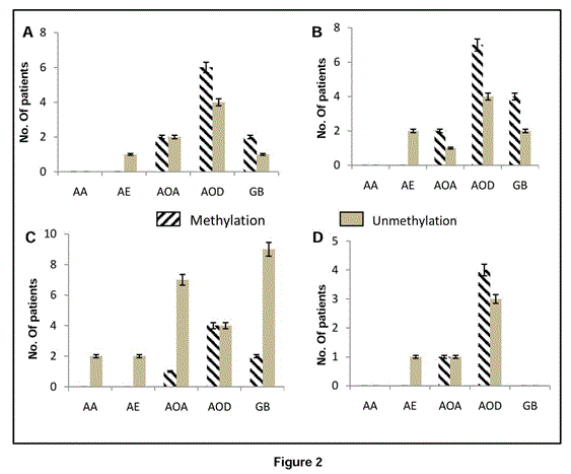

Figure 2: Distribution of two/three gene concurrent methylation pattern among tumor types Fig 2A shows MGMT-TP53 concurrent methylation status Fig 2B shows concurrent methylation status of $M G M T-C D K N 2 A$ and Fig 2C concurrent methylation status of TP53-CDKN2A Fig 2D Concurrent methylation status of all three genes MGMT, TP53 and CDKN2A. 
Citation: Jeru-Manoj Manuel, Debarati Ghosh, Narasinga Rao KVL, Sibin MK, Venkatesh HN (2016) Role of Concurrent Methylation Pattern of MGMT, TP53 and CDKN2A Genes in the Prognosis of High Grade Glioma. J Carcinog Mutagene 7: 250. doi: $10.4172 / 2157-2518.1000250$

Page 4 of 8

\begin{tabular}{|c|c|c|c|c|c|c|}
\hline \multicolumn{2}{|c|}{ Variables } & \multirow{2}{*}{$\begin{array}{c}\begin{array}{c}\text { No. of } \\
\text { Patients }\end{array} \\
25\end{array}$} & \multirow{2}{*}{\begin{tabular}{|c|}
$\begin{array}{c}\text { Mean survival } \\
\text { (months) }\end{array}$ \\
$11.83(10.10-13.55)$ \\
\end{tabular}} & \multirow{2}{*}{\begin{tabular}{|c|}
$\begin{array}{c}14 \text { months } \\
\text { PFS } \\
\text { proportion(\%) }\end{array}$ \\
57
\end{tabular}} & \multirow{2}{*}{$\begin{array}{c}\begin{array}{c}\text { Hazard } \\
\text { Ratio }\end{array} \\
1\end{array}$} & \multirow{2}{*}{\begin{tabular}{|c|}
$\begin{array}{c}P \\
\text { value }\end{array}$ \\
0.187
\end{tabular}} \\
\hline \multirow{2}{*}{ Age } & $\begin{array}{l}\leq 40 \\
\text { years }\end{array}$ & & & & & \\
\hline & $\begin{array}{l}>40 \\
\text { years }\end{array}$ & 23 & 10.22(9.09-12.30) & 34.9 & 1.82 & \\
\hline \multirow[t]{2}{*}{ Grade } & III & 31 & $12.88(11.84-13.91)$ & 71 & 1 & $<0.0001$ \\
\hline & IV & 17 & $8.2(6.06-10.36)$ & 0 & 6.60 & \\
\hline \multirow[t]{2}{*}{ Position } & Frontal & 31 & $11.63(10.10-13.15)$ & 49.9 & 1 & 0.284 \\
\hline & Others & 17 & $10.57(8.68-12.47)$ & 37.4 & 1.60 & \\
\hline \multirow[t]{3}{*}{ Therapy } & $\mathrm{CT}+\mathrm{RT}$ & 21 & $13.85(13.56-14.13)$ & 71.1 & 1 & $<0.0001$ \\
\hline & RT & 9 & 11.22(9.03-13.42) & 61.1 & 2.68 & \\
\hline & No & 18 & $8(5.94-10.06)$ & 0 & 7.60 & \\
\hline \multicolumn{7}{|c|}{ MGMT Methylation status } \\
\hline \multicolumn{2}{|c|}{ G-III Methylated } & 22 & $13.62(12.89-14.35)$ & 83.3 & 1 & 0.02001 \\
\hline \multicolumn{2}{|c|}{ Un-methylated } & 9 & $11.11(8.40-13.82)$ & 44.7 & 5.40 & \\
\hline \multicolumn{2}{|c|}{ G-IV Methylated } & 14 & $9.40(7.27-11.53)$ & 15.7 & 1 & 0.001 \\
\hline \multicolumn{2}{|c|}{ Unmethylated } & 3 & $2.67(1.60-3.74)$ & 0 & 5.96 & \\
\hline \multicolumn{7}{|c|}{ TP53 Methylation status } \\
\hline \multicolumn{2}{|c|}{ G-III Methylated } & 10 & $13.20(11.71-14.68)$ & 90 & 1 & 0.274 \\
\hline \multicolumn{2}{|c|}{ Unmethylated } & 21 & $12.72(11.37-14.07)$ & 56.8 & 3.03 & \\
\hline \multicolumn{2}{|c|}{ G-IV Methylated } & 4 & $4.25(0.83-7.67)$ & 25 & 3.54 & 0.016 \\
\hline \multicolumn{2}{|c|}{ Unmethylated } & 13 & $9.51(7.28-11.75)$ & 17.9 & 1 & \\
\hline \multicolumn{3}{|c|}{$\begin{array}{l}\text { CDKN2A Methylation } \\
\text { status }\end{array}$} & & & & \\
\hline \multicolumn{2}{|c|}{ G-III Methylated } & 11 & 13.10(11.43-14.77) & 90 & 1 & 0.345 \\
\hline \multicolumn{2}{|c|}{ Unmethylated } & 20 & $12.75(11.43-14.07)$ & 60.7 & 2.65 & \\
\hline \multicolumn{2}{|c|}{ G-IV Methylated } & 6 & $8.17(4.76-11.58)$ & 16.7 & 1.02 & 0.961 \\
\hline \multicolumn{2}{|c|}{ Unmethylated } & 11 & $8.18(5.48-10.88)$ & 35.4 & 1 & \\
\hline
\end{tabular}

\section{Survival analysis}

Follow-up data was obtained from all 48 patients. PFS and OS at 14 months were analysed separately for grade III tumors using univariate analysis (Table 2), as both the grades have different mean/median survival months [30]. Median OS was estimated for grade IV patients. Among the grades and type of tumors, grade III oligodendroglial tumors were seen to have higher PFS and OS. The PFS data obtained for all the variables analysed (Table 2).

\section{Correlation of Methylation status with survival}

\section{PFS}

Survival analysis was performed to understand the individual methylation status of these three genes (Table 2). Grade III patients with methylated MGMT promoter had a mean PFS of 13.62 months (12.89-14.35) and those with unmethylated promoter had mean PFS of 11.11 months (8.40-13.82) with a significant $p$ value of 0.026 . Patients with TP53 methylation had a mean PFS of 13.20 months (11.71-14.68) and for those with unmethylated promoter, mean PFS was 12.72 months (11.37-14.07). Similarly, patients with CDKN2A methylation had mean PFS of 13.10 months (11.43-14.77) and a mean PFS of 12.75 months (11.43-14.07) for those with unmethylated promoter (Table 2).

\begin{tabular}{|l|l|l|l|}
\hline Variable & Hazard ratio & $95 \%$ C.I. & P value \\
\hline MGMT & 1 & & 0.12 \\
\hline Methylated & 2.12 & $0.84-5.37$ & \\
\hline Unmethylated & \multicolumn{5}{|l|}{} \\
\hline TP53 (Grade IV) & 1 & & 0.03 \\
\hline Methylated & 0.24 & $0.07-0.88$ & \\
\hline Unmethylated & \multicolumn{3}{|}{} \\
\hline Adjuvant therapy & 1 & & 0.0001 \\
\hline Yes & 8.98 & $3.09-26.08$ & \\
\hline No &
\end{tabular}

Table 3: Multivariate analysis for Independent Prognostic risk factors.

Grade IV patients with methylated MGMT promoter had a mean PFS of 9.40 months (7.27-11.53) and those with unmethylated promoter had mean PFS of 2.67 months (1.60-3.74) with a significant $p$ value of $<0.01$. Patients with TP53 methylation had a mean PFS of 4.25 months (0.83-7.67) and for those with unmethylated promoter, mean PFS was 9.51 months (7.28-11.75) with a significant $p$ value of 0.016 . Patients with CDKN2A methylation had mean PFS of 8.17 months (4.76-11.58) and for those with unmethylated promoter mean PFS was of 8.18 months (5.48-10.88).

Mean PFS for patients with all three genes concurrent methylation was 13.20 months (11.80-14.60) and for concurrent unmethylation was 10.60 months (6.85-14.34). The details of three and two gene concurrent methylation are given (Table 4 ).

Table 2: Univariate analysis showing 14 month PFS proportion. 
Citation: Jeru-Manoj Manuel, Debarati Ghosh, Narasinga Rao KVL, Sibin MK, Venkatesh HN (2016) Role of Concurrent Methylation Pattern of MGMT, TP53 and CDKN2A Genes in the Prognosis of High Grade Glioma. J Carcinog Mutagene 7: 250. doi: $10.4172 / 2157-2518.1000250$

Page 5 of 8

\begin{tabular}{|c|c|c|c|c|c|}
\hline \multicolumn{2}{|l|}{ Variables } & \multirow{2}{*}{$\begin{array}{l}\begin{array}{l}\text { No. of } \\
\text { patients }\end{array} \\
6 \\
\end{array}$} & \multirow{2}{*}{$\begin{array}{l}\text { Mean survival (months) } \\
13.20(11.80-14.60)\end{array}$} & \multirow{2}{*}{$\begin{array}{l}14 \text { months PFS } \\
\text { proportion (\%) } \\
80\end{array}$} & \multirow{3}{*}{$\begin{array}{l}\mathbf{P} \text { value } \\
0.131\end{array}$} \\
\hline Concurrent methylation status of all three & MMM & & & & \\
\hline & UUU & 5 & $10.60(6.86-14.34)$ & 30 & \\
\hline \multirow{2}{*}{$\begin{array}{l}\text { Combinations of prognostic analysis of } \\
\text { concurrent MGMT:TP53 methylation }\end{array}$} & M M & 10 & $11.44(8.75-14.13)$ & 68.6 & \multirow[t]{2}{*}{0.172} \\
\hline & $\cup \cup$ & 8 & $9.25(5.84-12.66)$ & 25 & \\
\hline \multirow{2}{*}{$\begin{array}{l}\text { Combinations of prognostic analysis of } \\
\text { concurrent MGMT:CDKN2A methylation }\end{array}$} & M M & 13 & $12.72(11.41-14.04)$ & 55 & \multirow[t]{2}{*}{0.352} \\
\hline & $\cup \cup$ & 8 & $10.36(7.02-13.73)$ & 41.7 & \\
\hline \multirow{2}{*}{$\begin{array}{l}\text { Combinations of prognostic analysis of } \\
\text { concurrent TP53: CDKN2A methylation }\end{array}$} & M M & 7 & $11.88(9.22-14.56)$ & 68.6 & \multirow[t]{2}{*}{0.479} \\
\hline & $\cup \cup$ & 24 & $11.79(10.35-13.24)$ & 60.2 & \\
\hline
\end{tabular}

Table 4: Univariate analysis with concurrent methylation.

\section{OS of grade IV tumors}

Patients with grade IV tumors had median OS of 10 months (6-13) for MGMT methylated and 2 months (2-4) for MGMT unmethylated $(\mathrm{p}=0.0007)$ (Figure 3B). TP53 methylation had median OS of 3 months (1-10) and for unmethylated 10 months (6-13) ( $\mathrm{p}=0.016)$ (Figure 3C). CDKN2A methylated had median OS of 8.5 months (4-12) and for unmethylated it was 10 months $(5-13)(\mathrm{p}=0.960)$. Univariate analysis of MGMT methylation status with therapy showed a significant result $(\mathrm{p}<0.0001)$.

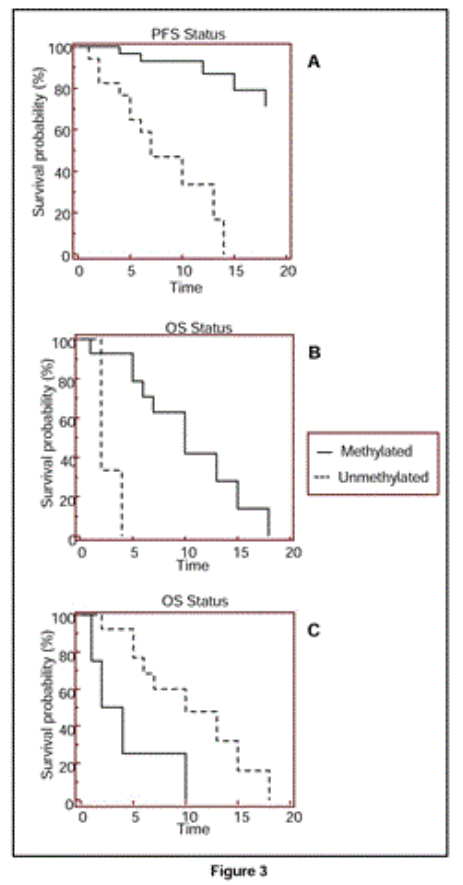

Figure 3: Survival graphs Fig 3A PFS with treatment status Figure 3B OS with MGMT methylation status Fig 3C OS with TP53 methylation status.
In multivariate analysis, we observed that MGMT unmethylation, TP53 methylation and no treatment were independent risk factors for faster progression of HGG (Table 3). The role of MGMT methylation status along with therapy was analysed to predict the PFS. The hazard ratio obtained was 8.98 (3.09 to 26.08) with a p value $<0.0001$, suggesting that MGMT unmethylated patients with no adjuvant therapy have a higher risk of progression.

\section{Discussion}

Promoter methylation is recognized as an important epigenetic mechanism of TSG inactivation during tumor development. Recent studies have shown that these epigenetic markers can be used as potential therapeutic targets to reverse the methylation $[6,7,31]$. Methylation is also known to play an important role in the recurrence of glioma [32]. Several prognostic markers studied in glioma have given rise to a paradoxical situation [33], therefore exploring new or validation of existing methylation biomarkers which may help glioma diagnosis, prognosis, or treatment decisions are important [8]. Understanding the association of concurrent promoter methylation status' between MGMT, TP53 and CDKN2A genes across different types of HGG and their relevance as to how they could determine tumor progression and influence survival is hence necessary. According to our knowledge, this is among the preliminary study to explore concurrence between the promoter methylation of these three genes which individually have important functional role in gliomagenesis.

In our cohort, promoter methylation of MGMT was seen in higher frequency, followed by CDKN2A and TP53. MGMT promoter methylation frequency was more in grade IV, in accordance with earlier reports on adult HGG which shows frequency to be between $60-85 \%$ [11,34,35]. Promoter methylation of the MGMT gene compromises DNA repair and has been associated with a longer PFS in glioma patients [36]. In our study, when MGMT methylation was correlated individually with PFS, it was found to be a good prognostic indicator with decreased tumor recurrence and improved OS. MGMT promoter methylation leads to reduced gene expression and is known to enhance adjuvant therapy response $[10,36]$. Similarly our patients with a methylated MGMT promoter who underwent adjuvant therapy had a better prognosis and longer survival as reported by other studies $[3,37]$. 
Citation: Jeru-Manoj Manuel, Debarati Ghosh, Narasinga Rao KVL, Sibin MK, Venkatesh HN (2016) Role of Concurrent Methylation Pattern of MGMT, TP53 and CDKN2A Genes in the Prognosis of High Grade Glioma. J Carcinog Mutagene 7: 250. doi: $10.4172 / 2157-2518.1000250$

Page 6 of 8

Concurrent methylation of MGMT with either of the other two genes, showed a similar distribution pattern especially in oligodendroglial tumors (Figure $2 \mathrm{~A} \& \mathrm{~B}$ ), this could be due to the similar biological function of TP53 and CDKN2A in the regulation of cell cycle. Grade III oligodendroglial component tumors were seen to have the highest frequency of concurrent methylation and showed a pattern quite different from other tumor types. The reason being, oligodendroglial tumors are known to have mutations in IDHlgene which induces an irregular CpG island methylation across the genome [38]. MGMT and TP53 are known to influence each other functionally; the formation of DNA adducts activate p53 controlled cell cycle as well as MGMT mediated DNA repair $[11,20]$. There are some reports showing lack of correlation between these two genes [21]. However, our analysis revealed the negative effect of TP53 methylation on PFS, when concurrent methylation between the MGMT: TP53 was observed. PFS proportion decreased to $68.6 \%$ as compared to PFS rate when MGMT was individually methylated (83.3\%). A similar association between concurrent methylation of MGMT: CDKN2A was observed. This could suggest a possible interdependency of methylation between these three genes.

Three gene concurrent methylation (MGMT:TP53:CDKN2A) was seen only in grade III tumors (mainly oligodendroglial) and showed the highest 14-month PFS rate of $80 \%$, whereas concurrent unmethylation had PFS rate of $30 \%$. Oligodendroglial tumors are known to have specific genetic markers not seen in the other histological types [39]. Likewise, concurrent methylation pattern could also be analysed by further studies, to see whether it can be made another signature. This may suggest that the occurrence of three gene concurrent methylation could also serve as a biomarker for analyzing recurrence of HGG. However, MGMT methylation among these three could be responsible for better PFS, evidenced by our study and other studies which have shown individual MGMT methylation to be a good prognostic indicator. Further, these patients with three gene concurrent methylation had increased PFS which could be attributed to adjuvant therapy (CT with TMZ+RT / RT) that they underwent.

TP53 is reported to have aberrant gene expression due to high mutations occurring in the gene, but its role in prognosis is still not clear between the different levels of expression observed [18]. TP53 methylation is reported to be more frequent in lower grade than higher grade tumors [25] and less frequent in primary glioma [18]. Our study showed Grade III tumors had slightly higher frequency of individual promoter methylation for TP53 and CDKN2A than grade IV, suggesting TP53 methylation frequency reduces with increasing grades. This could be due to the difference in characteristics between the grades, i.e., grade III tumors have faster uncontrolled mitosis, whereas grade IV are necrotic [40]. Individual TP53 methylation was found to be a significant indicator of poor prognosis in grade IV patients evidenced by faster tumor progression (PFS) and decreased OS, since silencing of TP53 increases mutant phenotype across the genome [41].

CDKN2A is altered (mutations and exon deletions) more frequently in HGG [42, 43], leading to irregular gene expression pattern, resulting in loss of cell cycle function [29]. We had previously reported that CDKN2A (p16) shows decreased expression in HGG which may be due to methylation and it's known to be a poor prognostic marker [44]. We observed about $35 \%$ CDKN2A methylation in both grades, as reported by earlier studies [45]. However, CDKN2A methylation individually did not show any such prognostic association in HGG. Concurrent methylation pattern of TP53:CDKN2A was distributed differently from MGMT:TP53 and MGMT:CDKN2A (Figure 1C), indicating related cell cycle function between TP53 and CDKN2A. Analysis among these three genes, suggest that CDKN2A methylation has no significant influence on the methylation pattern of other two genes, as suggested by few other studies $[10,46]$.

PFS and OS depend on many factors like, age, extent of resection, histology type, gene mutations, treatment, treatment response, etc. Studies have shown that treatment response is dependent on methylation status of some important genes [33, 47]. Summarizing, the current study revealed that gene silencing mediated by promoter methylation of TSG is a relatively common event in HGG and could be used as biomarkers. Data indicated MGMT methylation with or without adjuvant therapy, in both grades of HGG and TP53 unmethylation in grade IV has significant correlation with improved prognosis. Oligodendroglial tumors have higher frequency of concurrent methylation of these three genes and were found to have predictive significance, indicated by increased PFS proportion. It will be interesting to study global methylation pattern and status of other important altered genes like PTEN, DMBT1, RASSF1A, hMLH1, in the disease progression of HGG.

\section{Conclusion}

Exploring the individual and concurrent methylation panel of genes functioning in different pathways leading to gliomagenesis could add further knowledge in this direction. Our study conceptualises the importance of concurrent methylation pattern of these key genes and its probable role in progression of glioma, which could help in clinical decision making and patient management. Genomic studies which involve quantitative promoter methylation analysis/ bisulphite sequencing/microarray analysis correlated with mRNA expression would give improved understanding of the role of concurrent methylation of important genes.

\section{Authors Contributions}

JMM carried out the sample collection, genetic studies, conception and design, acquisition of data, interpretation of results, drafting and revising the manuscript. DG carried out the sample collection, genetic studies, conception and design, acquisition and analysing of data and drafting part of manuscript. CGK conceived of the study, and participated in its design coordination and helped to draft the manuscript, agree to be accountable for all aspects of the work in ensuring that questions related to the accuracy or integrity of any part of the work are appropriately investigated and resolved. NRKVL, DIB and SBMM have given final approval of the version to be published and agree to be accountable for all aspects of the work in ensuring that questions related to the accuracy or integrity of any part of the work are appropriately investigated and resolved. SMK, VHN, LCH and AS participated in the design of the study and performed the statistical analysis.

\section{Acknowledgement}

We duly acknowledge funding agencies UGC-MANF, New Delhi for supporting Ph.D program of Jeru-Manoj Manuel and DST-SERB, New Delhi for major funding of this work. Authors especially acknowledge Dr. Vijay K Kalia, Retd. Professor of Biophysics (NIMHANS), for providing the positive methylation control cell line, which was cultured in his laboratory. Authors also acknowledge neuropathologists at NIMHANS for grading of gliomas. 
Citation: Jeru-Manoj Manuel, Debarati Ghosh, Narasinga Rao KVL, Sibin MK, Venkatesh HN (2016) Role of Concurrent Methylation Pattern of MGMT, TP53 and CDKN2A Genes in the Prognosis of High Grade Glioma. J Carcinog Mutagene 7: 250. doi: $10.4172 / 2157-2518.1000250$

Page 7 of 8

\section{References}

1. Louis DN, Ohgaki H, Wiestler OD, Cavenee WK, Burger PC, et al. (2007) The 2007 WHO classification of tumours of the central nervous system. Acta Neuropathol 114: 97-109.

2. Boyle P, Lewin B (2008) World Cancer Report 2008.

3. Abhinav K, Aquilina K, Gbejuade H, La M, Hopkins K, et al. (2013) A pilot study of glioblastoma multiforme in elderly patients: treatments, O-6-methylguanine-DNA methyltransferase (MGMT) methylation status and survival. Clin Neurol Neurosurg 115: 1375-1378.

4. Philip-Ephraim EE, Eyong KI, Williams UE, Ephraim RP (2012) The role of radiotherapy and chemotherapy in the treatment of primary adult high grade gliomas: assessment of patients for these treatment approaches and the common immediate side effects. ISRN Oncol 2012: 902178.

5. Gan HK, Rosenthal MA, Dowling A, Kalnins R, Algar E, et al. (2010) A phase II trial of primary temozolomide in patients with grade III oligodendroglial brain tumors. Neuro Oncol 12: 500-507.

6. Burgess R, Jenkins R, Zhang Z (2008) Epigenetic changes in gliomas. Cancer Biol Ther 7: 1326-1334.

7. Bearzatto A, Szadkowski M, Macpherson P, Jiricny J, Karran P (2000) Epigenetic regulation of the MGMT and hMSH6 DNA repair genes in cells resistant to methylating agents. Cancer Res 60: 3262-3270.

8. Majchrzak-Celińska A, Paluszczak J, Szalata M, Barciszewska AM, Nowak S, et al. (2015) The methylation of a panel of genes differentiates lowgrade from high-grade gliomas. Tumour Biol 36: 3831-3841.

9. Esteller M, Hamilton SR, Burger PC, Baylin SB, Herman JG (1999) Inactivation of the DNA repair gene O6-methylguanine-DNA methyltransferase by promoter hypermethylation is a common event in primary human neoplasia. Cancer Res 59: 793-797.

10. Bhatia V, Goel MM, Makker A, Tewari S, Yadu A, et al. (2014) Promote region hypermethylation and mRNA expression of MGMT and p16 genes in tissue and blood samples of human premalignant oral lesions and oral squamous cell carcinoma. Biomed Res Int 2014: 248419.

11. Hermisson M, Klumpp A, Wick W, Wischhusen J, Nagel G, et al. (2006) O6-methylguanine DNA methyltransferase and p53 status predict temozolomide sensitivity in human malignant glioma cells. J Neurochem 96: 766-776.

12. Dunn J, Baborie A, Alam F, Joyce K, Moxham M, et al. (2009) Extent of MGMT promoter methylation correlates with outcome in glioblastomas given temozolomide and radiotherapy. Br J Cancer 101: 124-131.

13. Liang S, Shen G (2011) Biomarkers of Glioma. Mol Targets CNS Tumors.

14. Esteller M, Herman JG (2004) Generating mutations but providing chemosensitivity: the role of O6-methylguanine DNA methyltransferase in human cancer. Oncogene 23: 1-8.

15. Martínez R (2012) Beyond Genetics in Glioma Pathways: The EverIncreasing Crosstalk between Epigenomic and Genomic Events. J Signal Transduct 2012: 519807.

16. Everhard S, Tost J, E Abdalaoui H, Crinière E, Busato F, et al. (2009) Identification of regions correlating MGMT promoter methylation and gene expression in glioblastomas. Neuro Oncol 11: 348-356.

17. Hamilton DW, Lusher ME, Lindsey JC, Ellison DW, Clifford SC (2005) Epigenetic inactivation of the RASSF1A tumour suppressor gene in ependymoma. Cancer Lett 227: 75-81.

18. Jesionek-Kupnicka D, Szybka M, Malachowska B, Fendler W, Potemski P et al. (2014) TP53 promoter methylation in primary glioblastoma: relationship with TP53 mRNA and protein expression and mutation status. DNA Cell Biol 33: 217-226.

19. Rao SA, Srinivasan S, Patric IR, Hegde AS, Chandramouli BA, et al. (2014) A 16-gene signature distinguishes anaplastic astrocytoma from glioblastoma. PLoS One 9: e85200.

20. Grombacher T, Eichhorn U, Kaina B (1998) p53 is involved in regulation of the DNA repair gene O6-methylguanine-DNA methyltransferase (MGMT) by DNA damaging agents. Oncogene 17: 845-851.

21. Jesien-Lewandowicz E, Jesionek-Kupnicka D, Zawlik I, Szybka M, Kulczycka-Wojdala D,et al. (2009) High incidence of MGMT promoter methylation in primary glioblastomas without correlation with TP53 gene mutations. Cancer Genet Cytogenet 188: 77-82.

22. Esteller M, Toyota M, Montserrat Sanchez- Cespedes Capella G, Capella G, Peinado MA, et al. (2000) Inactivation of the DNA Repair Gene O 6 Methylguanine-DNA Methyltransferase by Promoter Hypermethylation Is Associated with $\mathrm{G}$ to $\mathrm{A}$ Mutations in $\mathrm{K}$-ras in Colorectal Tumorigenesis. Cancer Res 60: 2368-2371.

23. Shamsara J, Sharif S, Afsharnezhad S, Lotfi M, Raziee HR, et al. (2009) Association between MGMT promoter hypermethylation and p53 mutation in glioblastoma. Cancer Invest 27: 825-829.

24. Nakamura M, Watanabe T, Yonekawa Y, Kleihues P, Ohgaki H (2001) Promoter methylation of the DNA repair gene MGMT in astrocytomas is frequently associated with G:C --> A:T mutations of the TP53 tumor suppressor gene. Carcinogenesis 22: 1715-1719.

25. Amatya VJ, Naumann U, Weller M, Ohgaki H (2005) TP53 promoter methylation in human gliomas. Acta Neuropathol 110: 178-184.

26. Ribas C, Colleoni GW, Felix RS, Regis Silva MR, Caballero OL, et al. (2005) p16 gene methylation lacks correlation with angiogenesis and prognosis in multiple myeloma. Cancer Lett 222: 247-254.

27. Hara E, Smith R, Parry D, Tahara H, Stone S, et al. (1996) Regulation of p16CDKN2 expression and its implications for cell immortalization and senescence. Mol Cell Biol 16: 859-867.

28. Agirre X, Novo FJ, Calasanz MJ, Larráyoz MJ, Lahortiga I, et al. (2003) TP53 is frequently altered by methylation, mutation, and/or deletion in acute lymphoblastic leukaemia. Mol Carcinog 38: 201-208.

29. Fan X, Muñoz J, Sanko SG, Castresana JS (2002) PTEN, DMBT1, and p16 alterations in diffusely infiltrating astrocytomas. Int J Oncol 21: 667-674.

30. Lamborn KR, Yung WK, Chang SM, Wen PY, Cloughesy TF, et al. (2008) Progression-free survival: an important end point in evaluating therapy for recurrent high-grade gliomas. Neuro Oncol 10: 162-170.

31. Ducray F, El Hallani S, Idbaih A (2009) Diagnostic and prognostic markers in gliomas. Curr Opin Oncol 21: 537-542.

32. Gömöri E, Pál J, Kovács B, Dóczi T (2012) Concurrent hypermethylation of DNMT1, MGMT and EGFR genes in progression of gliomas. Diagn Pathol 7: 8.

33. Wager M, Menei P, Guilhot J, Levillain P, Michalak S, et al. (2008) Prognostic molecular markers with no impact on decision-making: the paradox of gliomas based on a prospective study. $\mathrm{Br} \mathrm{J}$ Cancer 98: 1830-1838.

34. Hegi ME, Diserens AC, Gorlia T, Hamou MF, de Tribolet N, et al. (2005) MGMT gene silencing and benefit from temozolomide in glioblastoma. $\mathrm{N}$ Engl J Med 352: 997-1003.

35. Oberstadt MC, Bien-Möller S, Weitmann K, Herzog S, Hentschel K, et al (2013) Epigenetic modulation of the drug resistance genes MGMT, $\mathrm{ABCB} 1$ and $\mathrm{ABCG} 2$ in glioblastoma multiforme. BMC Cancer 13: 617.

36. Weller M, Stupp R, Reifenberger G, Brandes AA, van den Bent MJ, et al. (2010) MGMT promoter methylation in malignant gliomas: ready for personalized medicine? Nat Rev Neurol 6: 39-51.

37. Chakravarti A, Erkkinen MG, Nestler U, Roger Stupp, Minesh Mehta, et al. (2006) Temozolomide-Mediated Radiation Enhancement in Glioblastoma?: A Report on Underlying Mechanisms Cancer Therapy?: Preclinical A Report on Underlying Mechanisms. Clin Cancer Res 12 : 4738-4746.

38. Ichimura K, Pearson DM, Kocialkowski S, Bäcklund LM, Chan R, et al. (2009) IDH1 mutations are present in the majority of common adult gliomas but rare in primary glioblastomas. Neuro Oncol 11: 341-347.

39. Masui K, Cloughesy TF, Mischel PS (2012) Review: molecular pathology in adult high-grade gliomas: from molecular diagnostics to target therapies. Neuropathol Appl Neurobiol 38: 271-291.

40. Maher EA, Furnari FB, Bachoo RM, Rowitch DH, Louis DN, et al. (2001) Malignant glioma: genetics and biology of a grave matter. Genes Dev 15: 1311-1333.

41. Saldaña-Meyer R, Recillas-Targa F (2011) Transcriptional and epigenetic regulation of the p53 tumor suppressor gene. Epigenetics 6: 1068-1077. 
Citation: Jeru-Manoj Manuel, Debarati Ghosh, Narasinga Rao KVL, Sibin MK, Venkatesh HN (2016) Role of Concurrent Methylation Pattern of MGMT, TP53 and CDKN2A Genes in the Prognosis of High Grade Glioma. J Carcinog Mutagene 7: 250. doi: 10.4172/2157-2518.1000250

Page 8 of 8

42. Kuo LT, Tsai SY, Chang CC, Kuo KT, Huang AP, et al. (2013) Genetic and epigenetic alterations in primary-progressive paired oligodendroglial tumors. PLoS One 8: e67139.

43. Sibin MK, Bhat DI, Lavanya CH, Manoj MJ, Aakershita S, et al. (2014) CDKN2A exon-wise deletion status and novel somatic mutations in Indian glioma patients. Tumour Biol 35: 1467-1472.

44. Sibin MK, Bhat DI, Narasingarao KV, Lavanya CH, Chetan GK (2015) CDKN2A (p16) mRNA decreased expression is a marker of poor prognosis in malignant high-grade glioma. Tumour Biol 36: 7607-7614.

45. Tverkuviene J, Laurinaviciene A, Daniunaite K, Scesnaite A, Jarmalaita S (2011) Frequent aberrant DNA methylation of CDKN2A locus in capillary hemangioblastomas, pheochromocytomas and gliomas. Acta medica Litu 18: 4-11.

46. Kato K, Hara A, Kuno T, Mori H, Yamashita T, et al. (2006) Aberrant promoter hypermethylation of p16 and MGMT genes in oral squamous cell carcinomas and the surrounding normal mucosa. J Cancer Res Clin Oncol 132: 735-743.

47. Sarkaria JN, Kitange GJ, James CD, Plummer R, Calvert H, et al. (2008) Mechanisms of chemoresistance to alkylating agents in malignant glioma. Clin Cancer Res 14: 2900-2908. 